\title{
The Incidence and Prevalence of Crohn's Disease in Global Scale
}

\author{
Payam Behzadi ${ }^{1}$, Elham Behzadi ${ }^{1}$, and Reza Ranjbar ${ }^{2 *}$ \\ ${ }^{1}$ Department of Microbiology, College of Basic Sciences, Shahr-e-Qods Branch, Islamic Azad University, Tehran, Iran \\ ${ }^{2}$ Molecular Biology Research Center, Baqiyatallah University of Medical Sciences, Tehran, Iran
}

Received: April 19, 2015; Accepted: May 08, 2015; Published: May 13, 2015

*Corresponding author: Reza Ranjbar, Molecular Biology Research Center, Baqiyatallah University of Medical Sciences, Tehran, Iran, Tel: +98-2188039883; Fax: +98-21-88039883; E-mail: ranjbarre@gmail.com

\begin{abstract}
The chronic and lifelong gastrointestinal tract disorder of Crohn's Disease (CD) is a type of inflammatory bowel disease with unclear causative agent. $C D$ is directly correlated with a triad group of predisposing factors including genetic problems, immune system malfunctions and environmental factors. The incidence and prevalence of $\mathrm{CD}$ in industrialized countries are high and in developing countries are low. However, industrial progressions have risen up the occurrence of $\mathrm{CD}$ in some developing countries in Asia and Africa. Because of some significant changes regarding to the incidence and prevalence of $\mathrm{CD}$ in global scale, the aim of this review article is to show the incidence and prevalence of CD worldwide.

For preparing this review, Google Scholar search engine and PubMed database were used to find the most recent and valuable original and review articles. The searched articles were then studied and sifted for writing the present review literature.

The results of different investigations show a significant increase among industrialized developing countries within Asia and Africa continents. Besides, the rate of $\mathrm{CD}$ is stable within western countries with no significant changes.

Continuous studies relating to the incidence and prevalence of $\mathrm{CD}$ will lead to discover the real causative agent of the disease. Moreover, detecting a diversity of the predisposing factors in different geographic areas may help to control and prevent the progression of $\mathrm{CD}$ in future.
\end{abstract}

Keywords: Crohn's Disease; Autoimmune disease; Anti Saccharomyces cerevisiae antibodies

\section{Introduction}

Inflammatory Bowel Disease (IBD) is known as a chronic sickness that involves $\mathrm{CD}$ and Ulcerative Colitis (UC). CD is a lifelong IBD which may affect any part of alimentary tract. The predominant age range of patients with $\mathrm{CD}$ is reported between 20 and 30; but it can happen at any age [1-3].

CD is usually recognized via clinical symptoms of diarrhea (with blood or/and mucus), fever, weight loss and abdominal pain. The ileocolonic lesions start with mucosal ulcers and change into fistulas by the time. About $80 \%$ of patients with CD have experienced a type of gut surgeries. The foci of $C D$ ulcers and lesions in patients are localized in determined parts of the gut including only small intestine (25\%), only large intestine $(20 \%)$, small and large intestines (50\%), and perianal zone (5\%) $[1,2,4]$.

The clear etiopathogenesis of $\mathrm{CD}$ is not recognized yet; but, there is a triangle of the main predisposing factors such as genetic, immunologic and peripheral parameters which triggers the disease. In other word, genetic malfunctions regarding to immune system in parallel with environmental factors like human gut microbiota, foods, smoke, chemical contamination induce the occurrence of $\mathrm{CD}$ in predisposed people. The environmental risk factors increase the appearance of CD in immune dysregulated individuals up to 40 times $[1,2,4,5,6]$.

According to epidemiological investigations, the prevalence of $\mathrm{CD}$ in industrialized countries is higher than developing countries. However, in recent years the rate of CD in industrialized countries has been stabilized while the number of patients with $\mathrm{CD}$ is rising up in developing countries. The progression of CD in developing countries is relating to changes in people's lifestyle. This feature has paled the idea that genetic characteristics rank in first $[4,6,7]$.

Because of some significant changes regarding to the incidence and prevalence of CD in global scale, the aim of this review article is to show the incidence and prevalence of $C D$ worldwide.

\section{Environmental Risk Factors}

The achievement of a wide range of scientific investigations has proved the strong influence of environmental factors on the occurrence of $\mathrm{CD}$ among different races and populations. The environmental factors are able to control the efficacy of genetic parameters. Thus, a known race or population with low risk of CD disease in their homelands (such as Asians and Hispanics) may be triggered for $\mathrm{CD}$ in an industrialized country and vice versa (e.g. Jews). Today, the role of environmental factors ranks first. Table 1 shows the most important environmental factors regarding to CD induction [4,6-9].

In parallel with environmental factors, genetic characteristics have been studied. Developments in Genetics and Bioinformatics 
resulted in identification of 163 susceptible loci for IBD in which 110 loci contribute in CD and UC $[4,6]$.

\section{Epidemiology}

Several studies show a high incidence and prevalence of CD in Western countries including USA, Canada, New Zealand, UK, Scandinavian area and Western Europe with stable increasing rate while CD is not a common autoimmune disease among African, Asian and Eastern European countries. Recent studies indicate a considerable increase of CD among industrialized developing countries such as a number of Asian countries [3,7,16,17].

The results of previous surveys in Western countries confirm a higher rate of $\mathrm{CD}$ among female patients in comparison with male populations; while this ratio is reversed in developing countries with a low incidence rate. Moreover there are two identified peaks for occurrence of $\mathrm{CD}$ among patients. The first peak appears in the age range of 15 to 35 and the second peak is happened in 60-80 year-old patients. The race and ethnical characteristics have no correlation with the appearance of $\mathrm{CD}$; because the recorded reports show that the disease occurs among immigrants in destination countries not in their homelands. This fact is detected within Asians and Hispanics who are living out of their homelands as immigrants $[3,4,6,18]$.

Until today, many statistical investigations in association with the prevalence of $\mathrm{CD}$ have been done around the world. The newest results are indicated in table 2 .

In epidemiologic studies, the rates of disease incidence and prevalence have their interpretations. Generally, the high incidence rate is in association with the presence of predisposing factors while the prevalence of a disease is correlated with geographical variations $[7,16]$.

In this review, we have studied the ranges of incidence and prevalence of $\mathrm{CD}$ in global scale. The results are presented as cases per $10^{5}(100,000)$ individuals regarding to annual incidence [table 2].

\section{Global Incidence and Prevalence of CD}

\section{The Persian Gulf region countries}

According to table 2, no complete data belonging to the all 8 countries of the Persian Gulf Region is available. The results of different studies in Iran and Saudi Arabia show a low incidence rate of $\mathrm{CD}$. However, the number of patients with $\mathrm{CD}$ is growing in Iran and Saudi Arabia. In addition to Iran and Saudi Arabia, the increase of CD is observed in the six left countries of the Persian Gulf Region too. Saudi Arabia owns the highest rates of incidence and prevalence of $\mathrm{CD}$ among the Persian Gulf Region countries $[2,8,9,19,21,29]$.

\section{Asia}

The rate of incidence and prevalence of CD in 12 large and crowded Asian countries is low. But, previous investigations indicate a significant increase of CD within Asian countries. The first three countries with highest incidence of CD involve Turkey, Lebanon and South Korea, respectively. On the other hand, Lebanon, Japan and South Korea rank as the first three countries with highest prevalence of $\mathrm{CD}$, respectively. Previous studies show that countries of South Korea, Japan and Hong Kong have experienced a significant increase of $\mathrm{CD}$ within last three decades $[2,7,16,17,20,22,23]$.

\section{Europe}

Although, the incidence and prevalence of CD in Europe are high, they vary in a vast range [Table 2] [7,16,20,23-25].

Among Western European countries Scotland has the highest incidence (11.7 per $10^{5}$ cases) and Switzerland ranks first with 100.7 per $10^{5}$ cases regarding to the prevalence of $\mathrm{CD}$. Finland, Denmark and Sweden own the highest incidence of CD with 9.2, 8.6, and 8.3 per $10^{5}$ cases; respectively while Sweden (213 per $10^{5}$ cases) and Denmark (151 per $10^{5}$ cases) rank first and second in the prevalence of CD in Northern Europe and even in whole Europe, respectively. The rate of CD (the incidence and prevalence) has been stabilized in Western Europe and especially in Scandinavian countries [7,16,20,23-25].

The incidence and prevalence of CD are considerably much lower in Eastern Europe. Hungary with the incidence of 8.9 per $10^{5}$ cases ranks first in association with $\mathrm{CD}$ and Bosnia Herzegovina owns the highest ranking for the prevalence of CD with 28.2 per $10^{5}$ cases among Eastern European countries. Last investigations reveal that, those countries from Eastern Europe which are trying to be modernized and industrialized are experiencing a high increase of the incidence and prevalence of CD. This feature

Table 1: The association of environmental factors with CD.

\begin{tabular}{|l|l|}
\hline Environmental factor & Effect \\
\hline Smoking [6,8] & $\begin{array}{l}\text { The most important environmental factor for inducing CD. It increases the occurrence of CD two times. An obvious } \\
\text { decrease in secretion of interleukin-8 (IL-8), IL-10 and IL-23 from mononuclear cells is recognized. }\end{array}$ \\
\hline Vitamin D [6] & $\begin{array}{l}\text { The loss of vitamin D leads to CD. Furthermore, sunlight is an indirect important factor for production of vitamin D } \\
\text { in people. The lack of sunlight leads to the absence of vitamin D and presence of CD. }\end{array}$ \\
\hline Antibiotics $[6,10-12]$ & $\begin{array}{l}\text { Some studies show that long time consumption of antibiotics increases the rate of CD [6]. While some other surveys } \\
\text { indicate that a long period consumption of a combination of two or more antibiotics has no clear positive effect on } \\
\text { CD. However, some studies show positive effects of antibiotic consumption on CD for a short time [10-12]. }\end{array}$ \\
\hline Chemical pollution $[4,6]$ & Chemical agent like NO ${ }_{2}$ rises up the risk of CD. \\
\hline Food Diet $[4,7,13,14]$ & Vegetable and fruits decrease the rate of CD while fast food increases the risk of CD. \\
\hline Season of birth $[9,15]$ & $\begin{array}{l}\text { Male patients born in April to June are predisposed for CD [15]. Another survey indicates no correlation between the } \\
\text { season of birth and CD [9]. }\end{array}$ \\
\hline
\end{tabular}


Table 2: The incidence and prevalence of Crohn's Disease in different countries.

\begin{tabular}{|c|c|c|c|}
\hline \multirow{2}{*}{ Region } & \multirow{2}{*}{ Country } & \multicolumn{2}{|c|}{ Crohn's Disese per $10^{5}$ cases } \\
\hline & & Incidence & Prevalence \\
\hline \multirow{8}{*}{$\begin{array}{l}\text { The Persian Gulf Region Countries } \\
\text { (Asia) }\end{array}$} & Bahrain & $\mathrm{NR}^{*}$ & NR \\
\hline & Iran [19] & 0.8 & - \\
\hline & Iraq & NR & NR \\
\hline & Kuwait [20] & - & - \\
\hline & Oman & NR & NR \\
\hline & Qatar & NR & NR \\
\hline & Saudi Arabia [21] & 1.91 & 6.72 \\
\hline & United Arab Emirate (UAE) & NR & NR \\
\hline \multirow{11}{*}{ Asia } & China [17] & 1.22 & - \\
\hline & Hong Kong [17] & 1.31 & - \\
\hline & India [17] & - & - \\
\hline & Indonesia [17] & 0.33 & - \\
\hline & Japan [17] & - & 21.2 \\
\hline & Malaysia [17] & 0.24 & - \\
\hline & Singapore [20] & - & 7.2 \\
\hline & South Korea [20] & 1.34 & 11.2 \\
\hline & Sri Lanka [17] & 0.59 & - \\
\hline & Thailand [17] & 0.3 & - \\
\hline & Turkey [22] & 2.2 & - \\
\hline \multirow{23}{*}{ Europe } & Bosnia and Herzegovina [23] & - & 28.2 \\
\hline & Croatia [23] & 6.5 & - \\
\hline & Czech [16] & 1.5 & - \\
\hline & Denmark [16] & 8.6 & 151 \\
\hline & Estonia [23] & 1.4 & - \\
\hline & Finland [24] & 9.2 & - \\
\hline & France [23] & 6.7 & - \\
\hline & Germany [23] & 6.6 & - \\
\hline & Hungary [23] & 8.9 & - \\
\hline & Iceland [23] & 5.5 & - \\
\hline & Ireland [25] & 6 & - \\
\hline & Italy [16] & 2.3 & 40 \\
\hline & Norway [25] & 5.8 & - \\
\hline & Poland [25] & Insignificant & Insignificant \\
\hline & Portugal [25] & 4.2 & - \\
\hline & Romania [16] & 0.5 & 8.3 \\
\hline & Russia [25] & NR & NR \\
\hline & Scotland [25] & 11.7 & - \\
\hline & Slovakia [25] & Insignificant & Insignificant \\
\hline & Spain [23] & 7.3 & - \\
\hline & Sweden [23] & 8.3 & 213 \\
\hline & Switzerland [23] & - & 100.7 \\
\hline & UK [23] & 6.6 & - \\
\hline \multirow{2}{*}{ North America } & Canada [16] & 20.2 & 319 \\
\hline & USA [26] & - & 241.3 \\
\hline \multirow{4}{*}{ Latin America } & Argentina [27] & Insignificant & Insignificant \\
\hline & Brazil [25] & 14.6 & - \\
\hline & Chile [25] & Insignificant & Insignificant \\
\hline & Panama [27] & - & - \\
\hline \multirow{2}{*}{ Oceania } & Australia [28] & 17.4 & - \\
\hline & New Zealand [28] & 15.2 & 145 \\
\hline Africa & South Africa [16] & 1.57 (Average) & - \\
\hline
\end{tabular}

NR*: Not Recorded 
is completely noticeable for Croatia; a considerable increase in the incidence of CD from 0.7 per $10^{5}$ (in 1989) to 6.5 (in 2004) [7,16,20,23-25].

\section{North America}

The incidence and prevalence of CD in North America are highest worldwide. There are several studies in different states of Canada and the USA. Canada ranks first relating to the incidence and prevalence of CD around the world. USA ranks second in association with the prevalence of CD both in North America and worldwide, previous reports from different states show a high increase of incidence and prevalence for CD. In recent decade, the rate of incidence and prevalence of $\mathrm{CD}$ has been stabilized [7,16,20,23-25].

\section{Latin America}

Latin America is consisted of Central and South America. Several researches indicate low levels for the incidence and prevalence of CD in Latin America. According to table 2, only Brazil encompasses high ranking in the incidence of $\mathrm{CD}$. The incidence and prevalence of CD in Panama (Central America), Argentina and Chile (South America) have been recorded insignificant and low $[7,16,17,20,23,25,27]$.

\section{Oceania}

Australia and New Zealand rank first and second for the incidence of $\mathrm{CD}$ within Oceania continent, respectively. The Oceania continent shows a remarkable high ranking for the incidence and prevalence of CD. Previous reports from 1980s relating to New Zealand show a very low incidence of 1.75 per $10^{5}$ for $\mathrm{CD}[7,16,23,28]$.

\section{Africa}

There are few recorded studies from Africa. Some reports from South Africa show a low rank for the incidence and prevalence of $\mathrm{CD}$. The results from African studies are classified into white, black and colored; However, we have indicated an average from three different records [7,16,25].

There are different types of diseases including bacterial infections, UC, celiac disease, food intoxication and CD which have similar clinical demonstrations. Therefore, laboratory and imaging tests must be performed. Microbiological assays involve stool culture, ELISA, microscopy and PCR for detecting pathogenic parasites (such as helminthes and their eggs, protozoaires and their ova), pathogenic bacteria (like Campylobacter, Escherichia coli, Salmonella spp. and Clostridium difficile) and viral agents, serologic tests for tracing anti-Escherichia coli antibodies (AECA) (against outer membrane), anti-Saccharomyces cerevisiae antibodies (ASCA), C-reactive protein (CRP) and anti-neurophil cytoplasmic antibodies (ANCA) [1-4,18].

Among different items relating to serologic tests, a positive result for ASCA represents a high possibility for CD suspended cases. The prevalence of ASCA+ patients with CD is reported within a range of $45 \%$ to $60 \%$ in global scale. The profile of CRP+/ ASCA+/ANCA- shows an active CD. A CRP+ serologic test devotes the active form of CD. The CRP+/ASCA-/ANCA+ profile belong to a patient with UC [1-4].

In parallel with microbiological and serological tests, histological biopsies and observations including colonoscopy, computed tomography (CT), endoscopy, fluoroscopy, magnetic resonance imaging (MRI), radiology, and ultrasonic radiations must be done [1-4].

\section{Conclusion}

CD is an autoimmune disease which is resulted from a multiple predisposing factors with unknown causative agent. Dysregulated immune system, genetic characterizations and environmental factors are considerable risk factors in patients with CD.

Although, genetic (ethnical/racial) characterizations are important items for occurring $\mathrm{CD}$, this is not a predominant agent. There are a vast range of environmental factors which effectively influence the occurrence of CD. Smoking, vitamin D, pollutants and food diet are remarkable environmental factors which directly stimulate genetic properties for the appearance of CD. The importance of sex, age, antibiotic consumption and seasons as other environmental parameters rank in second. According to table 2, Canada and the USA are the biggest countries that have a high ranking of fast foods. Simultaneously, in some states of Canada lacks sunlight. Besides, the range of smoking and level of chemical pollutions is high. These items are determined environmental factors that rising up the increase of CD in Canada and the USA. However in recent years, the rate of CD has been stabilized in both aforementioned countries.

The rate of CD in Latin American countries is low. However, some countries like Brasilia own high ranking of CD. Insignificant rates of $\mathrm{CD}$ are reported from Argentina, Chile and Panama. It seems that these countries suffer from some inaccuracies in their diagnostic techniques.

Western European countries have huge similarities with Canada and the USA in their lifestyle. Fast foods, lack of sunlight, chemical pollutions and smocking are predominant environmental items in a big part of Western Europe. Scotland, Switzerland, Scandinavian countries are suffering from these environmental parameters. Despite the high occurrence of CD in Western European countries, the rate of CD has been stabilized.

Eastern Europe countries possess a low ranking level in association with CD. However, those countries which are modernizing for being industrialized as well as Western European countries are experiencing significant increase in the rate of $C D$ occurrence. This is completely obvious in some countries such as Hungary, Croatia, and Bosnia Herzegovina.

Australia and New Zealand encompass high rates of CD. The high rate of $\mathrm{CD}$ in these countries is related to their modernized lifestyles. Smoking, chemical pollutions and fast food are predominated environmental factors in Oceania continent.

Africa experiences a low rate of CD. There are not enough studies and reports in this continent. Besides, the majority of 
African countries suffer from hunger and poor diagnostic tools.

The Persian Gulf Region countries are experiencing a significant increase in association with the rate of $\mathrm{CD}$. Modernization and industrializing are the most important factors. Moreover, the use of modern diagnostic tools may help to detect accurate cases in these countries. However, there is a considerable lack of data from the most countries located in the Persian Gulf Region, exclusive Iran and Saudi Arabia. The increase of smoking, chemical pollutions and western food diet is responsible for the increase of CD in the Persian Gulf Region countries.

Asia involves a wide range of countries with different characterizations. Japan, Hong Kong and South Korea are pioneers in high ranking rate of $\mathrm{CD}$. These aforementioned countries are experiencing industrialized societies from old pasts; so the high rate of $\mathrm{CD}$ is recognized from the past. Lebanon, Turkey and China are countries that are trying to be modernized; hence they are experiencing a new increase in the rate of CD. The most important environmental factors in these countries are smoking, chemical pollutions and fast food consumption.

Long time consumption of antibiotics and the season as environmental factors rank in second place among; because according to table 1 there is paradox information in association with the recent factors. The rate of mortality among patients with CD is high, worldwide. However, it has decreased in recent decades.

Finally we can conclude that environmental factors are dominated factors for changing the rate of $\mathrm{CD}$ in different countries. Besides, diagnostic procedures that are employed in enable specialists to detect and identify the disease with high accuracy and reliability.

Because of the importance of $\mathrm{CD}$, we suggest our colleagues to investigate and present the incidence and prevalence of $\mathrm{CD}$ in their countries; in particular, colleagues in the Persian Gulf Region countries.

\section{References}

1. Laass MW, Roggenbuck D, Conrad K. Diagnosis and classification of Crohn's disease. Autoimmunity reviews. 2014; 13(4-5): 467-471.

2. Behzadi P, Behzadi E, Ranjbar R. Autoimmunity, Crohn's disease and anti-Saccharomyces cerevisiae autoantibodies. farmacist.ro. 2014; 156(1): 50-52.

3. Pinzon MCM, Hayden DM. Crohn's Disease. Common Surgical Diseases: Springer. 2015; 161-163.

4. Baumgart DC, Sandborn WJ. Crohn's disease. The Lancet. 2012; 380(9853): 1590-1605. doi: 10.1016/S0140-6736(12)60026-9.

5. Khor B, Gardet A, Xavier RJ. Genetics and pathogenesis of inflammatory bowel disease. Nature. 2011; 474(7351): 307-317. doi: 10.1038/ nature10209.

6. Ananthakrishnan AN. Environmental triggers for inflammatory bowel disease. Current gastroenterology reports. 2013; 15(1): 302. doi: 10.1007/s11894-012-0302-4.

7. Logan I, Bowlus CL. The geoepidemiology of autoimmune intestinal diseases. Autoimmun rev. 2013; 9(5): A372-A8. doi: 10.1016/j. autrev.2009.11.008.

8. Safarpour AR, Hosseini SV, Mehrabani D. Epidemiology of inflammatory bowel diseases in iran and Asia; a mini review. Iran J Med Sci. 2013; 38(2 Suppl): 140-149.

9. Taghavi SA, Safarpour AR, Hosseini SV, Noroozi H, Safarpour M, Rahimikazerooni S. Epidemiology of Inflammatory Bowel Diseases (IBD) in Iran: A review of 740 patients in Fars province, Southern Iran. Ann Colorectal Res. 2013; 1(1): 17-22.

10. Selby W, Pavli P, Crotty B, Florin T, Radford-Smith G, Gibson P, et al. Two-year combination antibiotic therapy with clarithromycin, rifabutin, and clofazimine for Crohn's disease. Gastroenterology. 2007; 132(7): 2313-2319.

11. Thia KT, Mahadevan U, Feagan BG, Wong C, Cockeram A, Bitton A, et al. Ciprofloxacin or metronidazole for the treatment of perianal fistulas in patients with Crohn's disease: a randomized, double-blind, placebocontrolled pilot study. Inflamm Bowel Dis. 2009; 15(1):17-24. doi: 10.1002/ibd.20608.

12. Feller M, Huwiler K, Schoepfer A, Shang A, Furrer H, Egger M. Longterm antibiotic treatment for Crohn's disease: systematic review and meta-analysis of placebo-controlled trials. Clinical infectious diseases. 2010; 50(4): 473-80. doi: 10.1086/649923.

13. Chassaing B, Koren O, Goodrich JK, Poole AC, Srinivasan S, Ley RE, et al. Dietary emulsifiers impact the mouse gut microbiota promoting colitis and metabolic syndrome. Nature. 2015; 519(7541):92-96. doi: $10.1038 /$ nature14232.

14. Devkota S, Wang Y, Musch MW, Leone V, Fehlner-Peach H, Nadimpalli A, et al. Dietary-fat-induced taurocholic acid promotes pathobiont expansion and colitis in Il10-/-mice. Nature. 2012; 487(7405):104108. doi: 10.1038/nature11225.

15. Shaw SY, Nugent Z, Targownik LE, Singh H, Blanchard JF, Bernstein CN. Association between Spring Season of Birth and Crohn's Disease. Clin Gastroenterol Hepatol. 2014; 12(2):277-282. doi: 10.1016/j. cgh.2013.07.028.

16. Cosnes J, Gower-Rousseau C, Seksik P, Cortot A. Epidemiology and natural history of inflammatory bowel diseases. Gastroenterology. 2011; 140(6):1785-1794. e4. doi: 10.1053/j.gastro.2011.01.055.

17. Ng SC. Epidemiology of inflammatory bowel disease: Focus on Asia. Best Pract Res Clin Gastroenterol. 2014; 28(3):363-372. doi: 10.1016/j.bpg.2014.04.003.

18. Chan SS, Hart AR. Aetiology and Clinical Features of Crohn's Disease. Crohn's Disease: Springer. 2015; p. 1-9.

19.Zahedi MJ, Darvish Moghadam S, Hayat Bakhsh Abbasi M, Dehghani M, Shafiei Pour S, Zydabady Nejad H. Middle East J Dig Dis; 2014; 6(1):3236.

20. Thia KT, Loftus EV, Sandborn WJ, Yang S-K. An update on the epidemiology of inflammatory bowel disease in Asia. Am J Gastroenterol. 2008; 103(12): 3167-3182. doi: 10.1111/j.15720241.2008.02158.x

21. Al-Mofleh IA, Azzam NA. Crohn's disease. Increasing trend in Saudi Arabia. Saudi Med J. 2013; 34(11):1105-13.

22. Tozun N, Atug O, Imeryuz N, Hamzaoglu HO, Tiftikci A, Parlak E, et al. Clinical characteristics of inflammatory bowel disease in Turkey: a multicenter epidemiologic survey. J clin Gastroenterol. 2009; 43(1):51-7. doi: 10.1097/MCG.0b013e3181574636. 
23. Burisch J, Jess T, Martinato M, Lakatos PL. The burden of inflammatory bowel disease in Europe. J Crohn's Colitis. 2013; 7(4):322-37. doi: 10.1016/j.crohns.2013.01.010.

24. Jussila A, Virta LJ, Kautiainen H, Rekiaro M, Nieminen U, Färkkilä MA. Increasing incidence of inflammatory bowel diseases between 2000 and 2007: a nationwide register study in Finland. Inflamm Bowel Dis. 2012; 18(3):555-561. doi: 10.1002/ibd.21695.

25.Economou M, Zambeli E, Michopoulos S. Incidence and prevalence of Crohn's disease and its etiological influences. Annals of gastroenterology. 2009; 22(3):158-67.

26. Kappelman MD, Moore KR, Allen JK, Cook SF. Recent trends in the prevalence of Crohn's disease and ulcerative colitis in a commercially insured US population. Digestive diseases and sciences. 2013; 58(2): 519-525. doi: 10.1007/s10620-012-2371-5.

27. Linares dlCJ, Canton C, Hermida C, Perez-Miranda M, Mate-Jimenez J. Estimated incidence of inflammatory bowel disease in Argentina and Panama (1987-1993). Rev Esp Enferm Dig. 1999; 91(4):277-286.

28. Day AS, Lemberg DA, Gearry RB. Inflammatory Bowel Disease in Australasian Children and Adolescents. Gastroenterol Res Pract. 2014; 2014:703890. doi: 10.1155/2014/703890.

29. Mansour-Ghanaei F, Haghkerdar M, Joukar F, Aminian K, Mashhour MY, Shafaghi A, et al. Epidemiologic Features of Inflammatory Bowel Disease in Guilan Province, North of Iran, During 2002-2012. Middle East Journal of Digestive Diseases (MEJDD). 2015; 7(2): 69-74. 